\title{
Different combinations of perennial ryegrass and white clover phenotypes do not affect mixture yield under cutting management during establishment
}

L. ROSSI ${ }^{1}$, D.F. CHAPMAN ${ }^{2}$ and G.R. EDWARDS

${ }^{1}$ DairyNZ, Private Bag 3221, Hamilton 3240, New Zealand

2 DairyNZ, P.O. Box 160, Lincoln University, Lincoln 7647, New Zealand

${ }_{3}^{3}$ Agriculture and Life Sciences Faculty, Lincoln University, P.O Box 84, Lincoln University, New Zealand laura.rossi@dairynz.co.nz

\begin{abstract}
A field experiment was conducted for 12 month under irrigation and cutting management determine if interactions between perennial ryegrass and white clover cultivars of different phenotypes could affect pasture yield and botanical composition during establishment. Four ryegrass and four clover cultivars, differing in leaf and tiller/stolon traits, were grown in all combinations $(n=16)$, along with monocultures of each $(\mathrm{n}=8)$, as sub-plots under two nitrogen fertiliser levels (100 or $325 \mathrm{~kg} \mathrm{~N} / \mathrm{ha} /$ year). Dry matter yield and botanical composition were measured on nine occasions and ryegrass and clover population densities were determined four times. Total annual yield was similar for all mixture combinations due to substitution between the sward components. While there were significant yield differences among ryegrass or clover cultivar monocultures, these seldom explained differences in mixture yields. Mixtures yielded more DM than ryegrass monocultures under both $\mathrm{N}$ treatments $(+1.3$ to $+3.9 \mathrm{t} \mathrm{DM} / \mathrm{ha} /$ year)
\end{abstract}

Keywords: perennial ryegrass, white clover, dairy, dry matter yield, nitrogen fertiliser, phenotype, competition

\section{Introduction}

Perennial ryegrass (Lolium perenne) and white clover (Trifolium repens) are the main components of pastures in New Zealand. Generally, when ryegrass and clover cultivars of different phenotypes are grown in a mixture the total annual dry matter (DM) yield of the pasture is similar, although differences in botanical composition can occur (Reid 1961; Connolly 1968; Camlin 1981; Rhodes \& Harris 1979; Widdup \& Turner 1983; Ledgard et al. 1990). More ryegrass and clover cultivars with a greater phenotypic range are now available than when these above studies were undertaken. This raises the question as to whether interactions between modern cultivars can affect pasture yield and botanical composition to provide more productive pastures. This study addresses this question and examines how grass and clover characteristics may affect their competitive ability. Another objective was to quantify the effect of he inclusion of clover on pasture dry matter (DM) yield and its implications for ryegrass cultivar performance. The working hypothesis was that the DM production of the sward will not differ when modern perennial ryegrass and white clover cultivars with different ial ryegrass and four white clove cultivas grown in binary mixtures at different nitroge N) fertiliser levels were compared. The perennia ryegrass cultivar by white clover cultivar interaction term was considered the critical test of the hypothesis. Monocultures of all cultivars were also included to help separate the effects on mixture yields of variation among cultivars in yielding ability per se from phenotypic factors such as tiller or stolon density and leaf morphology.

\section{Methodology and analysis}

The experiment was sown in November 2013 at the Lincoln University Research Dairy Farm, Lincoln, Canterbury, New Zealand (latitude 433' 10.26 "S longitude $172^{\circ} 27^{\prime} 42.91$ 'E; altitude $12 \mathrm{~m}$ a.s.l.) an measurements were made from 1 June 2014 to 31 May 2015. Soils at the site were Paparua sandy loam and Wakanui sandy loam, typic immature pallic soils and and mottled immature pallic soils, respectively, (New during the experiment $(376 \mathrm{~mm})$ was $223 \mathrm{~mm}$ lower during the experiment $(376 \mathrm{~mm})$ was $223 \mathrm{~mm}$ lower
than the 30 year average $(1981$ to 2010$)$ of $599 \mathrm{~mm}$. than the 30 year average (1981 to 2010 ) of $599 \mathrm{~mm}$. Mean temperature for the period $\left(12.3^{\circ} \mathrm{C}\right.$ ) was $0.7^{\circ} \mathrm{C}$ Water and Atmospheric Research 2015).

The experimental design was a split-plot with four The exp. Min plots were two N levels (100 $\mathrm{N} / \mathrm{ha}$ /year), randomised within block Subplots were the pasture types (24), made up of a $4 \times$ 4 factorial of four perennial ryegrass cultivars and fou white clover cultivars (16 subplots), plus monocultures of each cultivar (8 subplots), randomised within main plots. Subplots were $3 \times 1.8 \mathrm{~m}$; from within that area, the 10 central drill lines $(1.5 \mathrm{~m}$ width) were harvested, resulting in a measurement area of $4.5 \mathrm{~m}^{2}$. Four 
perennial ryegrass cultivars were compared providing a range from fine to broader leaved and from open to denser plant habits. The cultivars were Abermagic AR1 (a dense, fine-leaved, diploid), Arrow AR1 (a dense, medium to broad-leaved, diploid), Prospect AR37 (a dense, medium to wide-leaved, diploid) and Bealey NEA2 (an open, medium-leaved, tetraploid). The four white clover cultivars evaluated represented a range in leaf size: Nomad (small-leaved), Bounty (mediumleaved), Tribute (medium-large-leaved) and Kopu II (large-leaved).

Sowing rates were $20 \mathrm{~kg} / \mathrm{ha}$ of seed for the diploid ryegrasses and $28 \mathrm{~kg} / \mathrm{ha}$ for the tetraploid ryegrass to account for differences in seed weight between the ploidy levels. White clover was sown at a rate of $4 \mathrm{~kg} /$ ha of bare seed (correction of this sowing rate was made to account for seed coating).

Defoliation was by cutting to avoid confounding animal effects; irrigation was applied from October 2014 to March 2015 (400 mm).

$\mathrm{N}$ fertiliser was applied manually as urea (46-0-0). In the Low N (100 kg N/ha) treatment, urea was applied at rates of $25 \mathrm{~kg} \mathrm{~N} / \mathrm{ha}$ on four occasions. In the High N $(325 \mathrm{~kg} \mathrm{~N} / \mathrm{ha}$ ) treatment, it was applied at a rate of 35.2 $\mathrm{kg} \mathrm{N} / \mathrm{ha}$ on six occasions and at a rate of $57 \mathrm{~kg} \mathrm{~N} / \mathrm{ha}$ for the last two applications.

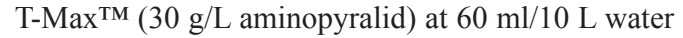
was applied on $3^{\text {rd }}$ January 2015, with a knapsack sprayer, to the perennial ryegrass monocultures to control white clover and other legumes. The same day Gallant ${ }^{\mathrm{TM}}$ Ultra $(520 \mathrm{~g} / \mathrm{L}$ haloxyfop-P) at $12 \mathrm{ml} / 10 \mathrm{~L}$ water with Uptake ${ }^{\mathrm{TM}}$ spraying oil $(582 \mathrm{~g} / \mathrm{L}$ paraffinic oil and $240 \mathrm{~g} / \mathrm{L}$ alkoxylated alcohol non-ionic surfactants) at $15 \mathrm{ml} / 10 \mathrm{~L}$ water were applied with a knapsack sprayer to the white clover monocultures to control perennial ryegrass and other grasses.

Total DM yield was estimated on nine occasions (the first on the 22 August 2014 and the last on 12 May 2015) by harvesting the entire $4.5 \mathrm{~m}^{2}$ measurement area to $5.5 \mathrm{~cm}$ above ground level, using a Haldrup forage harvester (Haldrup F-55, Denmark). Botanical composition was determined by dissecting a $15 \mathrm{~g}$ (fresh weight) subsample into: live perennial ryegrass, live white clover, live other species and dead material of all species. Components were dried for 72 hours at $65^{\circ} \mathrm{C}$. Perennial ryegrass and white clover population densities were measued duing J 2014 , Novenber densities were 2015 and May 2015 ; a $5 \times 20$ cm (100 2014 , Janiay 2015 and Ma 2015 ; a $5 \times 20 \mathrm{~cm}$ (100 $\mathrm{cm}^{2}$ ) fram in each subplot and the number of perennial ryegrass tillers and white clover growing points within each frame were counted.

Statistical analyses were conducted for mixtures, monocultures of perennial ryegrass and monocultures of white clover, using ANOVA in GenStat 17 (VSN
International 2014). Repeated measurements analyses were conducted on the total DM yield using the AREPMEASURES procedure in GenStat 17 (VSN International 2014). Perennial ryegrass and white clover yields $(\mathrm{kg} \mathrm{DM} / \mathrm{ha})$ within the mixture treatments were analysed by ANOVA (VSN International 2014). These yields were calculated based on the total DM and botanical composition data for each harvest. For the white clover content of mixtures (\% DM), the repeated ing spline models within the linear mixed model framework as described by Verbyla et al. (1999). Regression analyses were conducted between perennial ryegrass and white clover population density, population density and DM yield and between DM yields for monocultures and mixture.

\section{Results}

No interactions between perennial ryegrass and white clover cultivars on DM yield of the mixtures were observed, with one exception (Table 1). In November 2014, there was an interaction between N treatment perennial ryegrass cultivar and white clover cultiva $(\mathrm{P}=0.045)$. Mixtures including Arrow AR1 and Kopu II grown under the High $\mathrm{N}$ treatment yielded less than the same mixtures under the Low $\mathrm{N}$ treatment. Mixtures containing Abermagic $A R 1$ were the highest yielding Aber cultivar

The effect of perennial ryegrass cultivar on the DM yield of the mixture was significant in six of the nine harvests (Table 1). Mixtures sown with differen ryegrass cultivars were variable in their production, and the highest yielding mixture differed between harvests. Thus, total annual DM yield was similar irrespective of the perennial ryegrass cultivar included $(\mathrm{P}=0.089)$. White clover cultivar effect on the $\mathrm{DM}$ yield of a mixture was significant on only three occasions, resulting in a similar annual DM yield for the mixtures with different white clover cultivars $(\mathrm{P}=0.670)$.

Mixed pastures yielded $16.4 \%$ more than perennia ryegrass monocultures $(+2.6 \mathrm{t} \mathrm{DM} / \mathrm{ha}$, average of both $\mathrm{N}$ treatments); however, the increment due to inclusion of clover varied when the pastures were grown under the different $\mathrm{N}$ treatments $(\mathrm{N} \times$ white clover presence interaction, $\mathrm{P}<0.001)$. Mixtures with low $\mathrm{N}$ application te yielded $30.6 \%$ more $\mathrm{DM} / \mathrm{year}$ than perennial the same level of $\mathrm{N}(+3.9$ $\mathrm{DM} / \mathrm{ha}$ ), while mixed pastures yielded only $6.8 \%$ more than perennial ryegrass monocultures $(+1.3 \mathrm{t} \mathrm{DM} / \mathrm{ha})$ with high $\mathrm{N}$ application (Table 2).

Apart from the first harvest of the season (Augus 2014; data not presented) the white clover content (\% DM) of mixtures was greater under the Low than under 


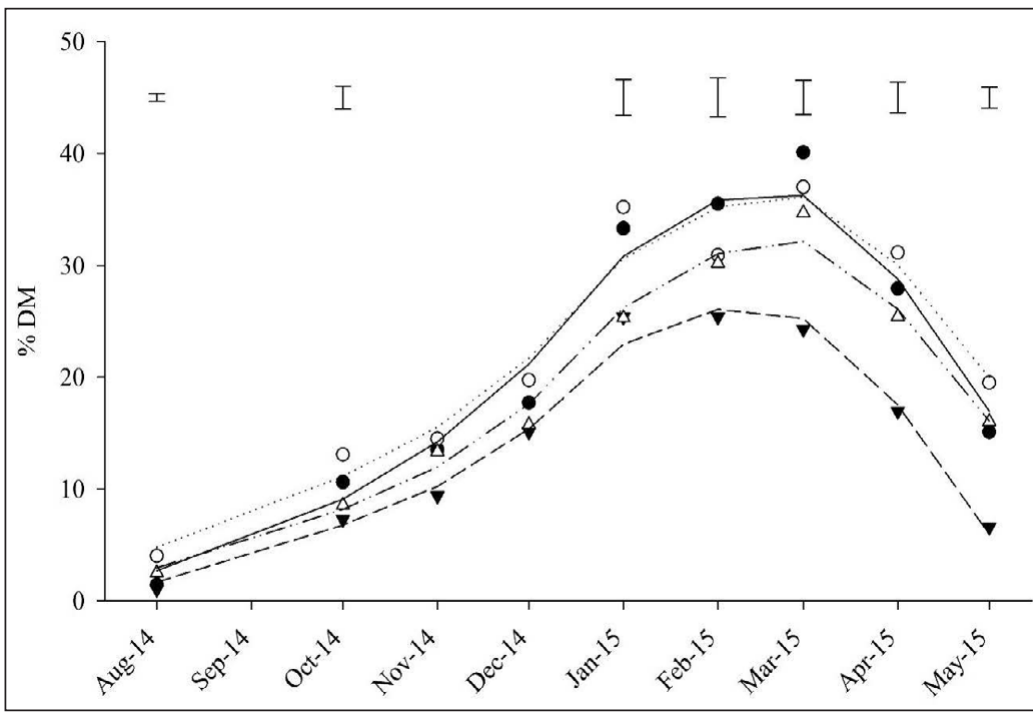

Figure 1 White clover content (\% of DM) of mixtures sown with different white clover cultivars (bars indicate SED - standard error of differences between means). Bounty Nomad ( $\nabla$ means raw data.- - spline curve), Tribute $(\triangle$ means raw data $\cdots$... spline curve). Data are means of two $\mathrm{N}$ levels.

January $2015(\mathrm{P}=0.220$ and 0.334 , respectively) Significant interaction between grass and clover cultivar on tiller density was detected only in November 2014 ( $\mathrm{P}=0.023)$.

Differences between clover cultivar monoculture growing point densities were significant at all four sampling times, with Bounty and Nomad most consistently having the most growing points $/ \mathrm{m}^{2}$. However, in mixture the effect of clover cultivar on growing point density only occurred in June 2014 $(\mathrm{P}=0.003)$. During the entire season, the number of clover growing points $/ \mathrm{m}^{2}$ was higher in monocultures than in mixtures.

the High $\mathrm{N}$ treatment The effect of perennial ryegras cultivar on clover content was greater in spring (Augus 2014, $\mathrm{P}<0.001$; October 2014, $\mathrm{P}=0.003$ ) and autumn (May 2015, $\mathrm{P}=0.001)$ ) whilst the effect of white clove cultivar occurred during most of the year (Figure 1). However, clover content was affected by the interaction between perennial ryegrass and white clover cultivar only once (May 2015, $\mathrm{P}=0.005$ ).

Ryegrass cultivars differed in tiller density at all four sampling times. The tetraploid, Bealey NEA2, had the lowest tiller density (no. $\left./ \mathrm{m}^{2}\right)$ both in monoculture and mixture. Mixed pastures had fewer tillers $/ \mathrm{m}^{2}$ than the perennial ryegrass monocultures in June $2014(\mathrm{P}<0.01)$ and May $2015(\mathrm{P}<0.001)$, but not in November 2014

\section{Discussion}

Mixture yields: interactions between grass and clover cultivars

Except for one date, no interactions between perennial ryegrass and white clover cultivars on DM yield of the mixtures occurred (November 2014). Thus, the hypothesis proposed is supported and breeding of both perennial ryegrass and white clover over recent decades has not altered the conclusion previously drawn, that interactions between perennial ryegrass and white clover cultivars do not affect the total yield of mixtures. This study found that monocultures of perennial ryegrass and white clover grew at similar rates from November to March (Table 1) and produced similar total annual DM yields, especially under low $\mathrm{N}$ application rate (Table 2). This suggests that substitution between the two pasture species largely negated any effects of grass cultivar by clover cultivar interactions on the total yield of binary mixtures.

White clover monocutie 12665 N (kg DM/kg N)'

\section{Mixture - total2} 14420 $18650 \quad 21.0$

-

19920

16635

0.5

11.9 in total mixture yield were seldom observed, significant differences in the yield of mixtures based on different ryegrass cultivars or different clover cultivars occurred in six and three of the nine months, respectively (Table 1). Perennial ryegrass dominated botanical composition of the mixtures throughout the study. White clover only contributed $50 \%$ or more of total pasture DM in January, February and March for pastures based on Bounty and Kopu II in the Low N treatment (data not presented; Figure 1 shows general trends in clover content; Hence, it is not surprising that significant differences in the yield of the mixtures differing in perennial ryegrass cultivar were observed more often than differences due to white clover cultivar. These findings agree with Camlin (1981) who compared perennial ryegrass/white clover mixtures fertilised with $200-240 \mathrm{~kg} \mathrm{~N} / \mathrm{ha} /$ year and observed that mixture yield tended to reflect the yield of the grass component.

The relative yields of mixtures based on different ryegrass cultivars aligned with relative differences in monoculture yields on only two of the six occasions (August and November) when ryegrass cultivar influenced mixture yields. Regression analyses confirmed that, in these 2 months, there was significant positive association between the mean perennial ryegrass cultivar yield in monoculture and in mixture (August: $\mathrm{P}=0.006 ; \mathrm{R}^{2}=0.989$; November: $\mathrm{P}=0.002$; $\left.\mathrm{R}^{2}=0.997\right)$. Both times, the relative yield of Abermagic AR1 strongly influenced the outcomes. Abermagic AR1 yielded markedly less than the three other ryegrass cultivars in August, but markedly more in November (Table 1). In the other 7 months of the year, perennial ryegrass cultivar yields in monoculture were similar. Meanwhile, tiller density differed consistently among the ryegrass cultivars. Hence, if ryegrass phenotypic characters such as tiller density exert sufficient influence on grass/clover interactions to alter the yield of mixtures, there was ample opportunity for this effect to emerge without any confounding effect of cultivar growth rate per se, but it did not eventuate.

Applying the same analysis to white clover, clover yields in monoculture aligned with differences in mixture yield based on the different clover cultivars on only one occasion (May 2015). Then, the largeleaved and medium-large leaved cultivars, Kopu II and Tribute, respectively, yielded more DM in monoculture than the small-leaved and medium-leaved cultivars Nomad and Bounty, respectively. This flowed through to relative yields of the mixtures based on the four cultivars, notably in the contrast between Tribute and Bounty (Table 1). Otherwise, there was opportunity for the consistent differences in stolon and leaf characters of the white clover cultivars observed throughout the study to influence mixture performance, but again, this did not eventuate.
Different conditions for pasture growth were created by the use of Low and High $\mathrm{N}$ application rates. $\mathrm{N}$ availability affects competition between grass and lover in mixtures. However, in general, no interaction between $\mathrm{N}$ and perennial ryegrass cultivar or $\mathrm{N}$ and white clover cultivar were detected.

Mostly, the causes of differences in mixture yields remain unexplained. While there were several statistically significant differences, in quantitative terms they were small and agronomically unimportant. The argest occurred in mixtures based on different ryegras cultivars in August and November (c. 1 and 0.5 tonne $\mathrm{DM} /$ ha, respectively) and, as described above, were explained by the yield of Abermagic AR1 relative to the other cultivars in monoculture.

However, these conclusions are drawn from only 1 year of data (covering the period 6 to 18 months postsowing) from pastures managed by cutting. Caution is herefore requed when extrapolating to longer time frames and to grazing. Most of the clover plants would have been in the tap-rooted phase of development that usually lasts between 1 and 2 years after sowing (Brock et al. 2000; Brock \& Hay 2001), and in which the legume tends to produce the greatest amount of DM per unit area (Widdup \& Barrett 2011). Therefore, the high clover yields observed here may not be present in established pastures when clover plants move into the clonal phase. The relationship between ryegrass and clover changes as mixed swards mature and factors such as defoliation frequency and height, and the addition of $\mathrm{N}$ to the system through clover fixation, can all modify competition between the species (Harris \& Thomas 1973; Schwinning \& Parsons 1996a, 1996b). Other aspects of the grass/cover association, such as pasture nutritive value and animal production (e.g. Crush et al. 2006), also need to be considered. Some of these aspects are being investigated by continuing measurements on the experiment into the third year post-sowing.

\section{Conclusions}

The finding that substitution between species led to similar yield of mixtures based on different binary combinations of perennial ryegrass and white clover cultivars agrees with previous research. It also reaffirms the statement of Stewart (2006): lifting overall pasture production from mixtures is challenging because

any increase in the ryegrass yield is often partially cancelled by decreased clover yields'.

\section{ACKNOWLEDGEMENTS}

The study was funded by New Zealand dairy farmer through DairyNZ Inc., project number RD 1414 Thanks to DairyNZ science and technical teams, Lincoln University, Lincoln University Research Dairy 
Farm staff, Field Service Centre staff and postgraduate students. Thanks to Barbara Dow and Alison Lister for their assistance with statistical analyses. Helpful review comments on the manuscript from Warwick Harris an Keith Widdup are gratefully acknowledged.

\section{REFERENCES}

Brock, J.L.; Albrecht, K.A.; Tilbrook, J.C.; Hay, M.J.M. 2000. Morphology of white clover during development from seed to clonal populations in grazed pastures. Journal of Agricultural Science 135 103-111. doi:10.1017/s0021859699008060

Brock, J.L.; Hay, M.J.M. 2001. White clover performance in sown pastures: a biological ecological perspective. Proceedings of the New Zealand Grassland Association 63: 73-83.

Camlin, M.S.1981. Competitive effects between ten cultivars of perennial ryegrass and three cultivars of white clover grown in association. Grass and Forage Science 36: 169-178. doi:10.1111/j.1365-2494.1981. tb01553.x

Connolly, V. 1968. A comparison of six white clover and three perennial ryegrass varieties under a system of grazing management. Irish Journal of Agricultura Research 7: 227-242.

Crush, J.R.; Woodward, S.L.; Eerens, J.P.J.; MacDonald K.A. 2006. Growth and milksolids production in pastures of older and more recent ryegrass and white clover cultivars under dairy grazing. New Zealand Journal of Agricultural Research 49: 119-135.

Harris, W.; Thomas, V.J. 1973. Competition among pasture plants III. Effects of frequency and heigh of cutting on competition between white clove and two ryegrass cultivars. New Zealand Journal of Agricultural Research 16: 49-58.

Hewitt, A.E. 2010. New Zealand soil classification (3rd Ed.). Lincoln, New Zealand: Manaaki Whenua Press, Landcare Research.

Ledgard, S.F.; Brier, G.J.; Upsdel, M.P. 1990. Effect of clover cultivar on production and nitrogen fixation in clover-ryegrass swards under dairy cow grazing. New
Zealand Journal of Agricultural Research 33: 243249

National Institute of Water and Atmospheric Research. (2015). CliFlo: The National Climate Database. Retrieved from http://cliflo.niwa.co.nz/

Reid, D. 1961. Factors influencing the role of clover in grass-clover leys fertilized with nitrogen at different rates. II. The effects of the variety of white clover on the yields of total herbage and clover. Journal of Agricultural Science 56: 155-160.

Rhodes, I.; Harris, W. 1979. The nature and basis of differences in sward composition and yield in ryegrass-white clover mixtures. British Grassland Society, Occasional Symposium 10: 55-60.

Schwinning, S.; Parsons, A.J. 1996a. Analysis of the coexistence mechanisms for grasses and legumes in grazing systems. Journal of Ecology 84: 799-813. doi:10.2307/2960553

Schwinning, S.; Parsons, A.J. 1996b. A spatially explicit population model of stoloniferous $\mathrm{N}$-fixing legumes in mixed pasture with grass. Journal of Ecology, 84: 815-826 doi:10.2307/2960554

Stewart, A.V. 2006. Genetic origins of perennial ryegrass (Lolium perenne) for New Zealand pastures Proceedings of the 13th Australasian Plant Breeding Conference. pp. 11-20.

Verbyla, A.P.; Cullis, B.R.; Kenward, M.G.; Welham, S.J. 1999. The analysis of designed experiments and longitudinal data by using smoothing splines. Journal of the Royal Statistical Society: Series C (Applied Statistics) 48:269-311. doi:10.1111/1467-9876.00154

SN International. 2014. GenStat for Windows 17th Edition [Computer software]. Hemel Hempstead, UK: VSN International.

Widdup, K.H.; Barrett, B.A. 2011. Achieving persistence and productivity in white clover. Grassland Research and Practice Series 15: 173-180.

Widdup, K.H.; Turner, J.D. 1983. Performance of 4 white clover populations in monoculture and with ryegrass under grazing. New Zealand Journal of Experimental Agriculture 11: 27-31.

\section{Reducing nitrogen fertiliser alters dairy shed effluent quality}

S.J. DENNIS

Grounded, Hardys Road, RD 1 Colgate 7673, New Zealand

samual@grounded.co.nz

Abstract

Dairy farmers using low rates of nitrogen fertiliser observed reduced odour in milking sheds, and a smaller Erowh restion. Effluent samples from four conventional (>100 kg $\mathrm{N} / \mathrm{ha} /$ year, high-fete') and three low-nitrogen $(\mathrm{N})$ fertiliser ( $<50 \mathrm{~kg} \mathrm{~N} / \mathrm{ha} /$ year, "low-fert") properties were collected in January 2017 and analysed for total N concentration, $\mathrm{N}$ form, mineral nutrient concentration and $\mathrm{pH}$. Total effluent $\mathrm{N}$ concentration was comparable between both classes of farm. However, low-fert properties had a higher proportion of $\mathrm{N}$ in organic forms as opposed to ammoniacal-N than high-fert properties (mean $75 \%$ and $59 \%$ organic on low- and high-fert properties, repectively, $\mathrm{P}<0.01$ ). Low-fert effluent also had a lower $\mathrm{pH}$, higher $\mathrm{P}$ concentration, and nearer optimal N:P ratio than effluent from highfert properties. It was hypothesised that reducing $\mathrm{N}$ fertiliser may result in more nutritionally-balanced effluent (N:P ratio), causing microbes to multiply more rapidly (lowering $\mathrm{pH}$ ), storing $\mathrm{N}$ in microbial biomass, reducing ammonia emissions and odour, and reducing the risk of $\mathrm{N}$ leaching from effluent applied to pasture.

Keywords: dairy shed effluent, nitrogen fertiliser, ammonia, organic $\mathrm{N}$, environmental loss

\section{Introduction}

Dairy shed effluent is a valuable source of nutrients for pasture plants on dairy farms (DairyNZ 2015). However, it is also a potential source of nutrient loss predoming is a the following pathways: antong volatilisation ( $\mathrm{Li}$ et al. 2014), nitrate leaching, and phosphorus runoff. Effluent is highly variable, and the characteristics of effluent will alter the quantity of nutrients available for loss via each pathway, and therefore the potential for environmental losses (Houlbrooke et al. 2011).

Nitrogen $(\mathrm{N})$ exists in effluent in both inorganic (ammonium $\left(\mathrm{NH}_{4}^{+}\right)$and nitrate $\left(\mathrm{NO}_{3}^{-}\right)$) and organic forms. Inorgaic $\mathrm{N}$ is susceptible to gase loss as fomm. dissolved dissolved organic nitrogen can leach, as a general rule, organic nitrogen is unlikely to be lost unless it is first converted to inorganic forms (Houlbrooke et al. 2011). Inorganic nitrogen is available to plants and can be rapidly used for growth. Therefore, effluent rich in ammonia and/or nitrate is likely to result in an mmediate plant growth response. However, organic nitrogen (other than urea) is slowly released for plant use, and slow-release nutrients may result in a higher ong-term pasture growth response per unit of $\mathrm{N}$ applied han soluble nutrient applications (Zaman et al. 2009).

Farm staff on properties in the study group using low rates of $\mathrm{N}$ fertiliser noticed a reduced odour in the milking shed, and also a reduction in the immediate visible pasture response to effluent application, compared with their expectations from past experience under conventional management (A. Lapping pers. comm.). This paper describes the results from a farmerfunded effluent analysis study designed to determine whether these observations were do to actual

\section{Methodology and analysis}

Seven dairy farms were chosen for this study. All were located on free-draining alluvial soil and annual rainfall was supplemented with irrigation. All farms were located between Greendale and Dunsandel, in Canterbury, New Zealand. On most farms herd size was 500-800 cows (one "low-fert" farm had 300 an one "high-fert" farm had 1500). All used twice-a-day milking at the time of sampling, most farms used daily acid wash and two alkali washes per week (one high-fert farm used only one alkali wash per week) Insufficient data were available on wash-down water use to determine whether dilution differed between farms. Three farms applied low total rates of $\mathrm{N}$ fertiliser (30$43 \mathrm{kgN} / \mathrm{ha} / \mathrm{yer}$, as both organic and synthetic forms), a four applied moderate to (100-350 kgN/ alyear, primarily as urea). These two categories were cefere " refers solely to nitrogen. Supplementary feed practices were comparable, with cows receiving a grain or PKE supplementary feed on most properties, although two low-fert and one high-fert property also fed seaweed and/or fish hydrolysate as an animal nutritional supplement.

Eleven effluent samples were collected on two dates in January 2017. Four farms (two low-fert, two high-fert) were sampled on 16 January. All seven farms were sampled on 30 January. Samples were 